\title{
The Importance of Addressing Depression and Diabetes Distress in Adults with Type 2 Diabetes
}

\author{
Michelle D. Owens-Gary, $P h D^{7}$, Xuanping Zhang, $P h D^{\prime}$, Shawn Jawanda, $M D^{2}$, \\ Kai McKeever Bullard, $P h D^{7}$, Pamela Allweiss, $M D^{7}$, and Bryce D. Smith, PhD' \\ 'Division of Diabetes Translation, Centers for Disease Control and Prevention, Atlanta, GA, USA; ${ }^{2}$ Oak Ridge Institute for Science and Education, \\ Oak Ridge, TN, USA.
}

People with type 2 diabetes often experience two common mental health conditions: depression and diabetes distress. Both increase a patient's risk for mortality, poor disease management, diabetes-related complications, and poor quality of life. The American Diabetes Association and the U.S. Preventive Services Task Force recommend routine evaluations for these conditions in adults for optimal disease management and prevention of lifethreatening complications. However, barriers exist within primary care and specialty settings that make screening for depression and diabetes distress challenging. Depression and diabetes distress influence diabetes self-care and diabetes control and barriers in clinical care practice that can hinder detection and management of psychosocial issues in diabetes care. This paper highlights opportunities to increase mental health screenings and provides strategies to help providers address depression and diabetes distress in patients with type 2 diabetes.

KEY WORDS: diabetes; depression; diabetes distress; primary care; providers.

J Gen Intern Med 34(2):320-4

DOI: $10.1007 / \mathrm{s} 11606-018-4705-2$

(C) Society ofGeneral Internal Medicine (This is a U.S. government work and not under copyright protection in the U.S.; foreign copyright protection may apply) 2018

\begin{abstract}
A pproximately 30 million people or $12.2 \%$ of the US adult population have diabetes. ${ }^{1}$ Diabetes self-care (diet, physical activity, and medication adherence) is critical to controlling hemoglobin $\mathrm{A} 1 \mathrm{C}(\mathrm{HbAlc})$, blood pressure, and cholesterol levels and for the prevention or delay of diabetes-related complications. ${ }^{2}$ Depression and diabetes distress can impede control of these factors, and both are common conditions in people with type 2 diabetes. ${ }^{3,4}$ Depression is present in about one in five adults with type 2 diabetes. ${ }^{5-7}$ Diabetes distress affects almost one third of adults with type 2 diabetes. ${ }^{3}$ Diabetes distress is distinct from depression, as it results from the emotional burden (e.g., worry, frustration, anger, burnout) of
\end{abstract}

Received July 26, 2018

Revised September 10, 2018

Accepted October 9, 2018

Published online October 22, 2018 managing type 2 diabetes. ${ }^{5,8}$ Depression and diabetes distress can also overlap; about $4.5 \%$ of adults with diabetes screen positively for both. ${ }^{9}$ Moreover, depression or depressive symptomatology exacerbates diabetes-related distress, with both conditions negatively affecting glycemic control. ${ }^{9}$

In people with type 2 diabetes, depression and diabetes distress are both associated with increased risk for mortality, work absenteeism, poor disease management, and poor health outcomes. ${ }^{5,10}$ Depression also increases the risk for macrovascular complications (e.g., coronary artery disease, peripheral arterial disease, stroke). ${ }^{11}$ People with type 2 diabetes who experience either depression or diabetes distress also risk developing microvascular complications (e.g., retinopathy, neuropathy, nephropathy). ${ }^{4}$ Health systems, such as the Veterans Administration and Kaiser Permanente and others, institute regular screening for depression in primary care. ${ }^{12,13}$ Yet, in systems without universal screening, these mental health conditions often go unrecognized or undertreated in people with type 2 diabetes. ${ }^{14}$

For optimal disease management, as well as the prevention of life-threatening complications, the American Diabetes Association emphasizes the recognition, treatment, and management of depression and diabetes distress in people with type 2 diabetes. ${ }^{15,16}$ Early recognition, routine screening, and the use of evidence-based treatment approaches for depression and diabetes distress can improve control of $\mathrm{HbAlc}$, blood pressure, and cholesterol, as well as overall health, and results in medical cost savings. ${ }^{16,17}$

\section{THE INFLUENCE OF DEPRESSION AND DIABETES DISTRESS ON DIABETES MANAGEMENT AND SELF- CARE}

Poor control of HbAlc, blood pressure, and cholesterol is associated with poor medication adherence. Compared to non-depressed patients with type 2 diabetes, those with depression are twice as likely to have poor adherence to medication for blood glucose, blood pressure, and cholesterol. ${ }^{18}$ Additionally, patients with high psychological distress, low social support, and low self-efficacy have symptoms associated with poorer diabetes self-care. ${ }^{19}$ Targeted, individualized behavioral interventions addressing these 
three psychosocial factors may help improve diabetes selfcare and patient outcomes.

A recent meta-analysis examined psychological (stress, depression, anxiety, coping), motivational (self-efficacy), and behavioral factors (adherence to diet, physical activity, medication, glucose self-monitoring, and appointment keeping) as predictors of self-care behaviors among adults with type 2 diabetes. ${ }^{20}$ Depression contributed to significantly lower physical activity and dietary adherence, while high stress levels predicted lower medication adherence. ${ }^{20}$ Additionally, motivational factors, such as self-efficacy and coping, positively correlated with better glycemic control. The authors conclude that interventions focused on depression and self-efficacy could improve metabolic control and diabetes selfmanagement.

\section{SCREENING RECOMMENDATIONS FOR DEPRESSION AND DIABETES DISTRESS}

The U.S. Preventive Services Task Force recommends universal screening for depression. ${ }^{21,22}$ The American Diabetes Association ${ }^{15}$ recommends regular depression and diabetes distress screenings, particularly if patients with type 2 diabetes experience comorbidities, diabetes-related complications, changes in life events, or changes in their diabetes treatment plan. Additionally, the American Diabetes Association ${ }^{15}$ and others $^{23}$ recommend that all patients with type 2 diabetes receive education and support to acknowledge that distress is common among people with diabetes.

Although recommendations by the American Diabetes Association and the U.S. Preventive Services Task Force emphasize the need for routine evaluation of adults for mental health conditions, barriers to specific screening for depression and diabetes distress still exist. ${ }^{22,24}$ These barriers often occur at the patient, provider, and practice level (see Table 1). For instance, patients who have type 2 diabetes and diabetes distress or depression may experience stigma or shame about having these conditions. Therefore, they may not be as open to talk about the emotional challenges they face in managing type 2 diabetes. Also, patients may not recognize the symptoms they have as being related to depression or diabetes distress. ${ }^{24}$ All of these factors influence whether people with type 2 diabetes express concern about depressive symptomatology or distress with their providers or whether patients get the care they need to address mental health conditions. ${ }^{24}$

Prior to national recommendations to do universal depression screening, studies in primary care settings found depression being recognized in only about $50 \%$ of patients with this condition. ${ }^{25-27}$ More recent data show that depression screening rates remain low among patients with type 2 diabetes in particular, especially if there is no documented history of depression. ${ }^{14}$ Unfortunately, in a study that examined 71 health care providers' approaches to screening and treating patients with type 2 diabetes for depression, only half reported ever using a depression screening tool in their practice. ${ }^{28}$ Limited training may be one reason providers do not address the mental health issues of their patients with diabetes. Also, providers may consider psychosocial concerns to be out of their area of expertise, which can influence whether they screen or refer patients for mental health consultations. ${ }^{24}$ All providers experience competing demands for their limited time with patients, which makes it difficult to conduct mental health assessments. ${ }^{28}$ Providers caring for patients with diabetes may also have trouble distinguishing somatic symptoms of depression or diabetes distress from symptoms of physical illness, which can make it hard to provide an accurate diagnosis. ${ }^{29}$

Barriers to screening for depression and diabetes distress also exist at the practice level. If a practice does not have access to mental health specialists, mental health screening tools, or a reminder system to alert providers to screen for mental health conditions on a routine basis, depression and diabetes distress may go undetected. ${ }^{14,28}$

Table 1 Perceived Barriers and Strategies to Address Psychological Conditions in Primary Care and Specialty Settings

\begin{tabular}{|c|c|c|}
\hline & Perceived barriers & Strategies to address barriers \\
\hline $\begin{array}{l}\text { Patient } \\
\text { level }\end{array}$ & $\begin{array}{l}\text { Stigma about mental health conditions } \\
\text { Denial of depression or diabetes distress } \\
\text { Lack of knowledge about depressive symptomatology or } \\
\text { diabetes distress }\end{array}$ & $\begin{array}{l}\text { Educate patients with diabetes about depression and diabetes distress } \\
\text { Inform patients about educational resources for depression and diabetes } \\
\text { distress and mental health services available }\end{array}$ \\
\hline $\begin{array}{l}\text { Provider } \\
\text { level }\end{array}$ & $\begin{array}{l}\text { Lack of or inadequate mental health training } \\
\text { Workload demands or time constraints } \\
\text { Managing physical condition (e.g., diabetes) takes up } \\
\text { providers' time } \\
\text { Perception of mental health issues being out of providers' } \\
\text { area of expertise or responsibility } \\
\text { Perception that patients may not follow through with } \\
\text { mental health referral }\end{array}$ & $\begin{array}{l}\text { Identify and participate in mental health trainings available for primary } \\
\text { care providers } \\
\text { Identify ways to incorporate evidence-based guidelines into clinical } \\
\text { practice } \\
\text { Explore ways to effectively manage and address mental health } \\
\text { conditions during diabetes clinic visits }\end{array}$ \\
\hline $\begin{array}{l}\text { Practice } \\
\text { level }\end{array}$ & $\begin{array}{l}\text { Lack of access to mental health specialists } \\
\text { Lack of access to diabetes distress, depression, and other } \\
\text { mental health assessment tools } \\
\text { Lack of a reminder system }\end{array}$ & $\begin{array}{l}\text { Explore opportunities to assess patients' mental health concerns in } \\
\text { regular diabetes clinic visits } \\
\text { Identify ways to develop alert systems in electronic health records for } \\
\text { depression and diabetes distress screenings }\end{array}$ \\
\hline
\end{tabular}




\section{SCREENING TOOLS TO ASSESS DEPRESSION AND DIABETES DISTRESS}

Numerous validated assessment tools are available to screen for depression severity and diabetes distress. A common screener and diagnostic tool for depression is the Patient Health Questionnaire-9, which performs well in patients with and without type 2 diabetes. $^{30-32}$ A Patient Health Questionnaire-9 cutoff score of 10 or higher is acceptable for detecting major depressive disorder $88 \%$ of the time. ${ }^{30}$

The Problem Areas in Diabetes Scale and the Diabetes Distress Scale are both good measures for detecting diabetes distress. ${ }^{33}$ The Problem Areas in Diabetes Scale is a 20-item self-report instrument that focuses on negative emotions related to having diabetes (e.g., fear, anger, frustration) and diabetes burnout. ${ }^{33}$ The Diabetes Distress Scale contains 17 items that assess the severity of problems and burden associated diabetes management. ${ }^{33}$ In a study of 628 people with both type 1 and type 2 diabetes, $43.6 \%$ of the participants reported distress scores over the Problem Areas in Diabetes Scale cutoff of 40 or higher, suggesting clinical distress. ${ }^{33}$ The Diabetes Distress Scale, with a cutoff criterion of 3 or higher, was more conservative in detecting distress among study participants compared to the Problem Areas in Diabetes Scale, with the difference being more than 10 percentage points. ${ }^{33}$

\section{STRATEGIES TO IMPROVE SCREENING FOR DEPRESSION AND DIABETES DISTRESS}

Given that multiple barriers can hamper screening for depression and diabetes distress among patients with type 2 diabetes, the use of multiple strategies could help increase screening opportunities in primary care and specialty settings. At the patient level, providing educational information about how common depression and diabetes distress are for people with type 2 diabetes could help educate patients about these mental health conditions. It could also help patients recognize their own emotional needs and become better advocates for their own mental health care, as well as be an opportunity for intervention or referrals, if needed. At the provider level, offering mental health training to providers of patients with diabetes could help them recognize depression and diabetes distress in their patients. Training can also help providers determine whether a mental health consultation is warranted. ${ }^{24}$ At the practice level, adding prompts to electronic health records can promote screening for depression and diabetes distress, re-evaluations, treatment, and referrals. ${ }^{14,25}$

\section{COLLABORATIVE CARE}

Providers can use collaborative care to improve diabetes outcomes among their patients with type 2 diabetes. ${ }^{14,34,35} \mathrm{Col}-$ laborative care is a range of complex interventions where multiple health care providers from different professions provide comprehensive services in a coordinated way to augment primary care. ${ }^{36}$ The collaborative care team typically includes a primary care provider (e.g., doctor, nurse), who coordinates care with management staff (e.g., social worker, case manager, psychologist, nurse). The team develops interventions that emphasize the use of problem-solving therapy and antidepressant medication, an increased intensity of care for patients who initially do not respond to depression treatment, and the development of a plan to prevent depression relapse. ${ }^{34}$

Collaborative team members can work together to determine if a patient's care should be adjusted to achieve specific goals and long-term benefits, especially if the patient presents with mental health conditions, such as depression or diabetes distress. Although collaborative care increases costs, studies found improved outcomes among adults with type 2 diabetes and depression and overall medical cost savings (about \$896) for inpatient and outpatient services over a 2-year period compared to usual care. ${ }^{17}$

\section{USE OF DIABETES SELF-MANAGEMENT EDUCATION AND SUPPORT TO IMPROVE DIABETES OUTCOMES}

Diabetes self-management education and support is an evidence-based process that provides people with diabetes with the knowledge, skills, and abilities needed to make informed decisions about their self-care. ${ }^{37}$ Studies on diabetes self-management education and support demonstrate its effectiveness in decreasing diabetes distress and depression and improvement in the overall quality of life in people with type 2 diabetes. ${ }^{37}$ A study examining the relationship between diabetes distress and glycemic control following participation in diabetes self-management education and support found a reduction in diabetes distress, and that it was associated with a $0.25 \%$ reduction in HbAlc over a 6 - and 12 -month period. ${ }^{35}$

To address diabetes distress, the American Diabetes Association recommends health care providers refer patients to diabetes self-management education and support to focus on individualized diabetes self-care needs, including concerns about their ability to maintain a diabetes treatment regimen and identifying coping strategies (e.g., exploring sense of selfefficacy, social support systems). ${ }^{16}$

\section{CONCLUSION}

Depression and diabetes distress can reduce control of $\mathrm{HbAlc}$, blood pressure, and cholesterol, treatment adherence, and overall health among patients with type 2 diabetes. People with both depression and diabetes distress may be at a higher risk of harm due to inadequate diabetes control than those who have only one of them or do not have either condition. The American Diabetes Association recommends that providers screen patients with diabetes for depression and diabetes distress during their initial visit and periodically thereafter. Incorporating validated depression and diabetes distress screening 
instruments into electronic health records simplifies the screening process and the collection of responses from patients, as well as improves the ability of providers to address the mental health needs of their patients. Positive screenings for depression or diabetes distress signal the need to connect patients with additional care, such as a collaborative care team or diabetes self-management education and support services. Evidence summarized here suggests that early screening, prevention, and treatment of depression or diabetes distress can result in better diabetes self-management and improved quality of life for people with type 2 diabetes.

Acknowledgements: The authors are grateful for comments and suggestions from Clarice Conley on earlier drafts of this article.

Corresponding Author: Michelle D. Owens-Gary, PhD; Division of Diabetes Translation Centers for Disease Control and Prevention, 4770 Buford Highway, NE, MS-F75, Atlanta, GA 30341, USA (e-mail: mowens1@cdc.gov).

\section{Compliance with Ethical Standards:}

Conflict of Interest: The authors declare that they do not have a conflict of interest.

Disclaimer: The findings and conclusions in this report are those of the authors and do not necessarily represent the official position of the Centers for Disease Control and Prevention.

\section{REFERENCES}

1. CDC. National Diabetes Statistics Report, 2017: Estimates of diabetes and its burden in the United States. Atlanta, GA: CDC, 2017.

2. Stark Casagrande S, Fradkin JE, Saydah SH, Rust KF, Cowie CC. The prevalence of meeting A1C, blood pressure, and LDL goals among people with diabetes, 1988-2010. Diabetes Care 2013;36(8):2271-2279. https://doi.org/10.2337/dc12-2258.

3. Perrin NE, Davies MJ, Robertson N, Snoek FJ, Khunti K. The prevalence of diabetes-specific emotional distress in people with type 2 diabetes: a systematic review and meta-analysis. Diabet Med 2017;34(11):1508-20. https://doi.org/10.1111/dme.13448.

4. Ascher-Svanum H, Zagar A, Jiang D, et al. Associations between glycemic control, depressed mood, clinical depression, and diabetes distress before and after insulin initiation: an exploratory post hoc analysis. Diabetes Ther 2015;6(3):303-16. https://doi.org/10.1007/ s13300-015-0118-y.

5. Fisher L, Skaff MM, Mullan JT,Arean P, Glasgow R, Masharani U. A longitudinal study of affective and anxiety disorders, depressive affect and diabetes distress in adults with type 2 diabetes. Diabet Med 2008;25(9):1096-1101. https://doi.org/10.1111/j.1464-5491.2008. 02533.x.

6. Albertorio-Diaz JR, Eberhardt MS, Oquendo M, et al. Depressive states among adults with diabetes: findings from the National Health and Nutrition Examination Survey, 2007-2012. Diabetes Res Clin Pract 2017;127:80-8. https://doi.org/10.1016/j.diabres.2017.02.031.

7. American Diabetes Association. Depression. 2013. Available at: http:// www.diabetes.org/living-with-diabetes/complications/mental-health/ depression.html. Accessed 22 May 2018.

8. Roy M, Sengupta N, Sahana PK, et al. Type 2 diabetes and influence of diabetes-specific distress on depression. Diabetes Res Clin Pract 2018;143:194-8. https://doi.org/10.1016/j.diabres.2018.07.006.

9. Snoek J, Bremmer MA, Hermanns N. Constructs of depression and distress in diabetes: time for an appraisal. Lancet Diabetes Endocrinol 2015;3:450-60. https://doi.org/10.1016/S2213-8587(15)00135-7.

10. Zhang X, Norris SL, Gregg EW, Cheng YJ, Beckles G, Kahn HS. Depressive symptoms and mortality among persons with and without diabetes. Am J Epidemiol 2005; 161(7):652-60. https://doi.org/10.1093/ aje/kwi089.
11. Lin EHB, Rutter CM, Katon W, et al. Depression and advanced complications of diabetes: a prospective cohort study. Diabetes Care 2010;33(2):264-9. https://doi.org/10.2337/dc09-1068.

12. VA/DoD clinical practice guideline for the management of major depressive disorder. Available at: https://www.healthquality.va.gov/guidelines/ MH/mdd/VADoDMDDCPGFINAL82916.pdf. Accessed 29 Aug 2018.

13. Adult and adolescent depression screening, diagnosis, and treatment guideline. Available at: https://wa.kaiserpermanente.org/static/pdf/ public/guidelines/depression.pdf Accessed 29 Aug 2018.

14. Barnacle M, Strand MA, Werremeyer A, Maack B, Petry N. Depression screening in diabetes care to improve outcomes: are we meeting the challenge? Diabetes Educ 2016;42:646-51. https://doi.org/10.1177/ 0145721716662917.

15. American Diabetes Association. Lifestyle management. Diabetes Care 2017;40(suppl 1):S33-43. https://doi.org/10.2337/dc17-S007.

16. Young-Hyman D, de Groot M, Hill-Briggs F,Gonzalez JS, Hood $\mathbf{K}$, Peyrot M. Psychosocial care for people with diabetes: a position statement of the American Diabetes Association. Diabetes Care 2016;39(12):2126-40. https://doi.org/10.2337/dc16-2053.

17. Katon W, Unutzer J, Fan MY, et al. Cost-effectiveness and net benefit of enhanced treatment of depression for older adults with diabetes and depression. Diabetes Care 2006;29(2):265-70. https://doi.org/10.2337/ diacare.29.02.06.dc05-1572.

18. Katon W, Russo J, Lin EH, et al. Diabetes and poor disease control: is comorbid depression associated with poor medication adherence or lack of treatment intensification? Psychosom Med 2009;71(9):965-72. https://doi.org/10.1097/PSY.0b013e3181bd8f55.

19. Walker RJ, Gebregziabher M, Martin-Harris B, Egede LE. Understanding the influence of psychological and socioeconomic factors on diabetes self-care using structured equation modeling. Patient Educ Couns 2015;98(1):34-40. https://doi.org/10.1016/j.pec.2014.10.002.

20. Brown SA, Garcia AA, Brown A, et al. Biobehavioral determinants of glycemic control in type 2 diabetes: a systematic review and metaanalysis. Patient Educ Couns 2016;99(10):1558-67. https://doi.org/10. 1016/j.pec.2016.03.020.

21. U.S. Preventive Services Task Force. Screening for depression: recommendations and rationale. Ann Intern Med 2002;136:760-4. https://doi. org/10.7326/0003-4819-136-10-200205210-00012.

22. Siu AL, and the U.S. Preventive Services Task Force. Screening for depression in adults: US Preventive Services Task Force recommendation statement. JAMA 2016;315(4):380-7. https://doi.org/10.1001/jama. 2015.18392.

23. Fisher L, Gonzalez JS, Polonsky WH. The confusing tale of depression and distress in patients with diabetes: a call for greater clarity and precision. Diabet Med 2014;31(7):764-72. https://doi.org/10.1111/dme. 12428.

24. Johansen C, Torenholt R, Hommel E, Wittrup M, Cleal B, Willaing I. Barriers to addressing psychological problems in diabetes: perspectives of diabetologists on routine diabetes consultations in Denmark. J Psychol Psychother 2014;4(2):1-6. https://doi.org/10.4172/2161-0487. 1000141.

25. Egede LE. Failure to recognize depression in primary care: issues and challenges. J Gen Intern Med 2007;22(5):701-3. https://doi.org/10. 1007/s11606-007-0170-Z.

26. Mitchell AJ, Vaze A, Rao S. Clinical diagnosis of depression in primary care: a meta analysis. Lancet2009;374:609-19. https://doi.org/10. 1016/S0140-6736(09)60879-5.

27. Hermanns N, Caputo S, Dzida G, Khunti K, Meneghini LF, Snoek F. Screening, evaluation and management of depression in people with diabetes in primary care. Prim Care Diabetes 2013;7:1-10. https://doi. org/10.1016/j.pcd.2012.11.002.

28. Osborn CY, Kozak C, Wagner $\mathbf{J}$. Theory in practice: helping providers address depression in diabetes care. $J$ Contin Educ Heal Prof 2010;30(3):172-9. https://doi.org/10.1002/chp.20078.

29. Barley EA, Murray J, Walters P, Tylee A. Managing depression in primary care: a meta-synthesis of qualitative and quantitative research from the UK to identify barriers and facilitators. BMC Fam Pract 2011;12:47. https://doi.org/10.1186/1471-2296-12-47.

30. Kroenke K, Spitzer RL, Williams JBW. The PHQ-9. J Gen Intern Med 2001;16(9):606-13. https://doi.org/10.1046/j.1525-1497.2001. 016009606.x.

31. Janssen EP, Kohler S, Stehouwer CD, et al. The Patient Health Questionnaire-9 as a screening tool for depression in individuals with type 2 diabetes mellitus: the Maastricht study. J Am Geriatr Soc 2016;64(11):e201-6. https://doi.org/10.1111/jgs.14388. 
32. Kroenke K, Spitzer RL, Williams JBW. The PHQ-9: validity of a brief depression severity measure. J Gen Intern Med 2001.16:606-13. https://doi.org/10.1046/j.1525-1497.2001.016009606.x.

33. Schmitt A, Reimer B, Kulzer B, Haak T, Ehrmann D, Hermanns N How to assess diabetes distress: comparison of the Problem Areas in Diabetes Scale (PAID) and the Diabetes Distress Scale (DDS). Diabet Med 2015; 33:835-43. https://doi.org/10.1111/dme.12887.

34. Katon WJ, von Korff M, Lin EHB, et al. The pathways study: randomized trial of collaborative care in patients with diabetes and depression. Arch Gen Psychiatry 2004;61:1042-9. https://doi.org/10. 1001/archpsyc.61.10.1042.

35. Zagarins SE, Allen NA, Garb JL, Welch G. Improvement in glycemic control following a diabetes education intervention is associated with change in diabetes distress but not change in depressive symptoms. J Behav Med 2012;35(3):299-304. https://doi.org/10.1007/s10865-0119359-z.

36. Gilbody S, Bower P, Fletcher J, Richards D, Sutton AJ. Collaborative care for depression: a cumulative meta-analysis and review of longerterm outcomes. Arch Intern Med 2006;166(21):2314-21. https://doi. org/10.1001/archinte.166.21.2314.

37. Powers MA, Bardsley J, Cypress M, et al. Diabetes self-management education and support in type 2 diabetes: a joint position statement of the American Diabetes Association, the American Association of Diabetes Educators, and the Academy of Nutrition and Dietetics. Diabetes Care 2015; 38(7):1372-82. https://doi.org/10.2337/dc15-0730. 